\title{
Bacteriological profile of gram negative nosocomial isolates from intensive care units and their antibiogram in a tertiary care hospital of South India
}

\author{
Zarrin Afroz ${ }^{1, *}$, Basavaraj C. Metri ${ }^{2}$, Faisal N. Gilani ${ }^{3}$, Jyothi P. ${ }^{4}$ \\ ${ }^{1,3,4}$ Assistant Professor, ${ }^{2}$ Associate Professor, ${ }^{1,2,4}$ Dept. of Microbiology, ${ }^{3}$ Dept. of Forensic Medicine, ${ }^{1,3} \mathrm{G}$ S Medical College \& \\ Hospital, Pikhuwa, Uttar Pradesh, ${ }^{2,4}$ Sri B. M. Patil Medical College and Hospital, BLDE University, Vijayapura, Karnataka, \\ India
}

*Corresponding Author:

Email: zafroz36@gmail.com

\begin{abstract}
Introduction: Nosocomial infection is a key factor in determining clinical outcomes among patients admitted in intensive care units .Studies on nosocomial infections in ICUs found that respiratory tract infections, blood stream infections, urinary tract infections and soft tissue infections are the common nosocomial infections in ICUs. These infections are more commonly caused by Gram negative isolates. These organisms isolated are highly resistant to antibiotics. Early recognition of bacteria and appropriate antimicrobial therapy are essential for controlling infection, preventing the morbidity and improve the quality of life. Objectives: To find out the profile of Gram negative bacteria causing nosocomial infection in patients admitted in intensive care units. To know the antibiotic susceptibility pattern of the nosocomial isolates.

Materials and Methods: A total of 192 culture positive samples were taken from various clinical specimens. The organisms were identified by Gram staining, cultural characteristics and a battery of biochemical tests. Drug susceptibility was performed on the isolates by Kirby Bauer's disk diffusion method.

Results: A total of 202 organisms were isolated from 192 various clinical samples. Respiratory tract infection 76( 39.6\%) was the most common infection in Intensive care units .The number of Gram positive isolates was $60(29.7 \%) .142(70.3 \%) \mathrm{Gram}$ negative organisms were isolated. Among the Gram negative isolates Escherichia coli 46 (22.8\%) was the most frequently isolated organism followed by Klebsiella species 34(16.8\%). Highest occurrence of nosocomial infections was observed in CCU $52(27.1 \%$ ) followed by ICCU 48 ( 25\%).Among Gram negative bacilli minimum resistance was seen against imipenem (26.8\%)followed by piperacillin - tazobactam (45.1\%) and amikacin ( $47.9 \%)$.

Conclusion: This study shows that Gram negative bacteria were the major cause of infections in intensive care units. The most common isolates were Esch.coli followed by Klebsiella sp, and Acinetobacter sp. For Gram negative isolates the most effective antibiotics were imipenem followed by piperacillin - tazobactam and amikacin .Appropriate antibiotic utilization in Intensive Care Units is crucial not only in ensuring an optimal outcome but also in preventing multidrug resistant bacteria.
\end{abstract}

Keywords: Nosocomial isolates, Gram negative bacteria, Antibiotic susceptibility pattern.

\section{Introduction}

An infection is considered as nosocomial infection or Healthcare-Associated Infection (HAI) if it occurs within 48 hours after hospitalization, or after 3 days of discharge or 30 days after operation. According to CDC (Centre for disease prevention and control) guidelines The National Nosocomial Survillence System (NNIS) states that nosocomial infection results from an adverse reaction to the presence of an infectious agent or toxin that was not presenting or incubating at the time of admission to the hospital. Recently CDC guidelines states that the date of event of the NHSN (National healthcare safety network) site-specific infection criterion occurs on or after the 3rd calendar day of admission to an inpatient location where day of admission is calendar day $1 .{ }^{1,2}$

Nosocomial infection is a key factor in determining clinical outcomes among patients admitted in intensive care units. Critically ill patients in intensive care unit (ICU) are 5- 10 times more likely to acquire nosocomial infections than those in general wards. ${ }^{2,3}$

Studies on nosocomial infections in ICUs found that respiratory tract infections, blood stream infections, urinary tract infections and soft tissue infections are the common nosocomial infections in ICUs. Samples of urine, blood, pus, sputum and endotracheal secretions when evaluated had Gram negative isolates followed by Staphylococcus aureus, Coagulase negative Staphylococcus species and Enterococcus species. Among the Gram negative bacterial isolates there is a high prevalence of Pseudomonas among the ICU patients followed by Eschereshia coli, Klebsiella pneumoniae, Acinetobacter species and Citrobacter species. $^{4,5}$

These organisms isolated are highly resistant to antibiotics. Previous studies have shown that for Gram negative isolates the drugs which have been most effective are amikacin followed by imipenem. Imipenem has proved to be most effective against majority of the isolates \& has proved as a reliable agent for empirical treatment of majority of the ICU isolates. ${ }^{6}$

The consequences depend on the source involved, organisms associated, underlying morbidity, timeliness and appropriateness of interventions received. This may be related to the use of large number of invasive monitoring devices, endotracheal and tracheostomy tubes, factors like extremes of age, immunocompromised status, malnutrition, severe 
underlying disease, wide use of antibiotics and high incidence of cross infection. $^{2}$

The incidence and prevalence of multidrug resistant organisms are so high in the hospital settings that even effective drugs like fluoroquinolones, third generation cephalosporins, aminoglycosides etc. are fast loosing their utility in covering hospital pathogens, thus restricting the choice of antimicrobials for treating serious infections. Early recognition of bacteria and appropriate antimicrobial therapy are essential for controlling infection, preventing the morbidity and improve the quality of life. Since limited data are available concerning infection, mortality rates and antibiotic susceptibility of Gram negative pathogens in our hospital settings, therefore the present study will be taken to determine the types, frequency of nosocomial Gram negative bacterial isolates and their antibiotic susceptibility pattern.

\section{Materials and Methods}

The present study was undertaken at the department of Microbiology, BLDEUs Shri B. M. Patil medical college and hospital, Vijayapur during the period from 01-01-2014 to 30-06-2015. The study included a total of 192 culture positive samples taken from patients of both sexes irrespective of age groups admitted in the ICUs of BLDEUs, Shri B.M.Patil medical college, hospital and research centre, Vijayapur.

Inclusion criteria: Samples collected after 48 hours of admission of the patient to neonatal ICU( NICU), surgical ICU (SICU), pediatric ICU (PICU), Intensive cardiac care unit( ICCU) and critical care unit (CCU were included. Single or mixed growth from patients were included in the study.

Exclusion criteria: Anaerobic, fungal organisms, repeat samples from the same patient and samples collected before 48 hours of admission of the patient to ICU were excluded.

Blood samples were collected under aseptic precautions in blood culture bottles. Urine specimens from catheterised patients were collected in universal containers .Respiratory samples like sputum and endotracheal aspirates were collected in sqat, wide mouth disposable containers. Throat Swabs were placed in swab transport system containing stuart's transport medium and sent to lab. Pus from superficial wound samples were collected with swab and from deep wounds it was aspirated and collected in sterile small screw capped bottles. The containers were labelled with the name of patient, identification number, culture site, date of collection and time of collection .The specimens were transported to the laboratory within 30 minutes to 2 hours. The samples were inoculated on Nutrient agar, Blood agar and Mac Conkey's medium for samples other than urine. Urine samples were inoculated on CLED agar and Mac Conkey's medium. The media were incubated at $37^{\circ} \mathrm{C}$ for $24-48$ hours. The isolates were identified by Gram staining, colony morphology and standard biochemical tests.

Antibiotic susceptibility tests was done on Gram negative isolates by standard Disc diffusion method according to CLSI guidelines. The discs used were ampicillin $\quad(10 \mu \mathrm{g}), \quad$ cloxacillin $(10 \mu \mathrm{g})$, ciprofloxacin $(5 \mu \mathrm{g}), \quad$ cefuroxime $\quad(30 \mu \mathrm{g})$, cephalexin $(30 \mu \mathrm{g})$, ceftriaxone $(30 \mu \mathrm{g})$, gentamicin $(10 \mu \mathrm{g})$ amikacin $(30 \mu \mathrm{g}), \quad$ cotrimoxazole $(25 \mu \mathrm{g})$, piperacillin $\quad(100 \mu \mathrm{g}), \quad$ piperacillin-tazobactam $(100 / 10 \mu \mathrm{g})$, tetracycline $(30 \mu \mathrm{g})$, ciprofloxacin $(5 \mu \mathrm{g})$ and imipenam $(10 \mu \mathrm{g})$. For Gram negative organisms isolated from urine samples nitrofurantoin $(300 \mu \mathrm{g})$ discs were used. ${ }^{8}$

\section{Statistical analysis}

It was carried out by SPSS 14 software and data was analysed

1. In the form of percentage with tables

2. By diagrammatic presentation in the form of pie charts and graphs

\section{Results}

A total of 202 organisms were isolated from 192 various clinical samples. Most of the isolates were from respiratory specimens [sputum 38, endotracheal secretion 32 and throat swab 6] 76 (39.5\%) followed by pus samples $44(22.9 \%)$. The distribution of various clinical samples is shown in Table 1.

Table 1: Distribution of various clinical samples received from different ICUs

\begin{tabular}{|l|c|c|}
\hline \multicolumn{1}{|c|}{ Specimen } & No & $\begin{array}{c}\text { Percentage } \\
(\%)\end{array}$ \\
\hline Respiratory specimens & 76 & $39.5 \%$ \\
\hline 1. Sputum 38(19.8\%) & \multicolumn{2}{|l|}{} \\
\hline 2. ET secretion 32(16.7\%) \\
\hline 3. Throat swab 06(3.1\%) \\
\hline Pus & 44 & $22.9 \%$ \\
\hline Urine & 40 & $20.8 \%$ \\
\hline Blood & 32 & $16.7 \%$ \\
\hline Total & 192 & $100 \%$ \\
\hline
\end{tabular}

Most of the samples obtained were from males 116 $(60.6 \%)$ and $76(39.6 \%)$ were from females. The major age group was 1 day - 1 year which included 40 (20.9\%) samples followed by $41-50$ years and 61-70 years which included $26(13.5 \%)$ samples .The demographic characteristics of the study is shown in Fig 1. 
Fig 1: Demographic characteristics of the study

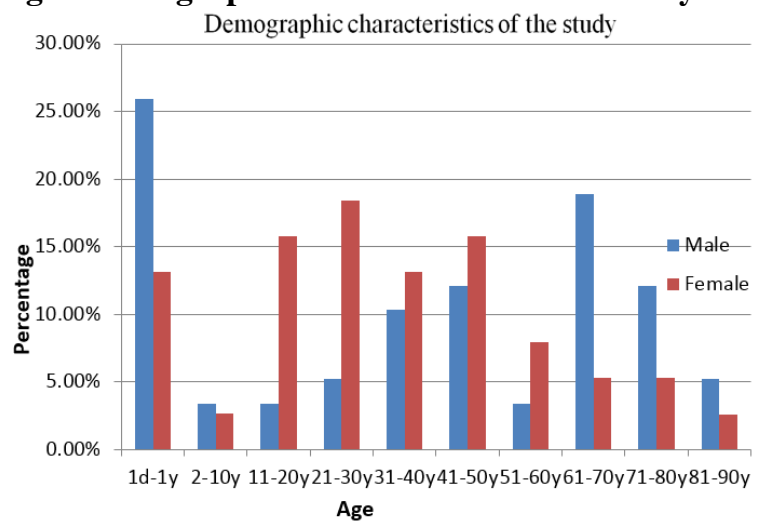

Respiratory tract infection 76(39.6\%) was the most common infection in Intensive care units. It was followed by skin and soft tissue infection $44(22.9 \%)$, urinary tract infection $40(20.8 \%)$ and blood stream infection $32(16.7 \%)$. The distribution of nosocomial infections is shown in Fig. 2.

Fig 2: Distribution of nosocomial infections in ICUs

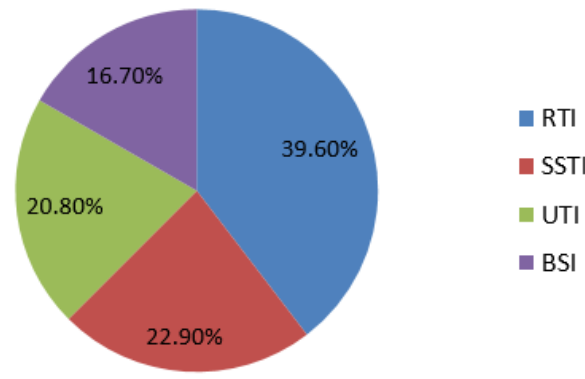

Out of the 192 samples processed 202 organisms were isolated. From 182 samples single organism was isolated. 10 samples had mixed growth. The number of Gram positive isolates was $60(29.7 \%)$ and $142(70.3 \%)$ Gram negative organisms were isolated. Among the Gram negative isolates Escherichia coli 46 (32.4\%) was the most frequently isolated organism followed by Klebsiella species $34(23.9 \%)$ and Acinetobacter species $32(22.5 \%)$. The distribution of Gram negative organisms is shown in (Table 2).

Table 2: Bacteriological profile of Gram negative organisms isolated from ICUs

\begin{tabular}{|l|c|c|}
\hline \multicolumn{1}{|c|}{ Organisms } & No & $\begin{array}{c}\text { Percentage } \\
(\mathbf{\%})\end{array}$ \\
\hline 1.Escherichia coli & 46 & $32.4 \%$ \\
\hline 2.Klebsiella species & 34 & $23.9 \%$ \\
\hline 3.Acinetobacter species & 32 & $22.5 \%$ \\
\hline 4.Pseudomonas aeruginosa & 22 & $15.5 \%$ \\
\hline 5.Citrobacter species & 8 & $5.6 \%$ \\
\hline Total & 142 & $100 \%$ \\
\hline
\end{tabular}

Highest occurrence of nosocomial infections was observed in CCU 52(27.1\%) followed by ICCU 48 $(25 \%)$. Majority of the respiratory tract infections were seen in ICCU $30(39.5 \%)$, skin and soft tissue infections in SICU 26(59.1\%), urinary tract infections in CCU $16(40 \%)$ and blood stream infections in NICU $30(93.7 \%)$. (Fig. 3).

Fig 3: Distribution of nosocomial infections in different ICUs

Distribution of nosocomial infections in ICUs

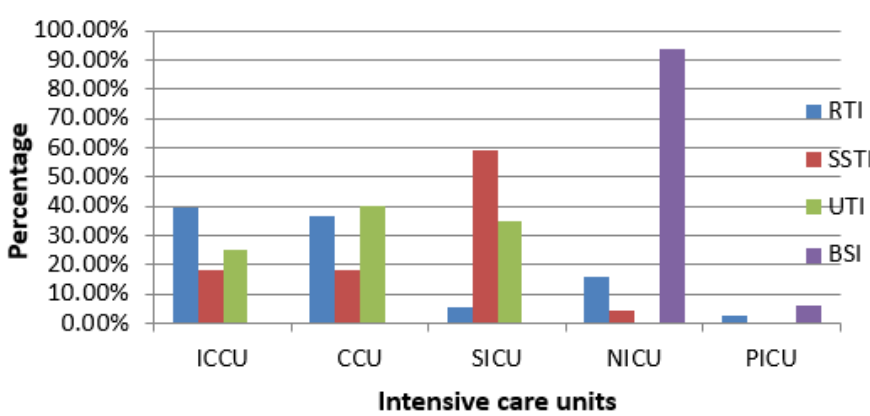

The most common nosocomial infection caused by Escherichia coli 24 (52.2\%) was urinary tract infection. 24 (70.6\%) of the Klebsiella species caused respiratory tract infection. The major infection caused by Acinetobacter species $14(43.7 \%)$ was respiratory tract infection.12 (54.5\%) of Pseudomonas aeruginosa was responsible for respiratory tract infection.4 (50\%) of Citrobacter species caused skin and soft tissue infections. The distribution of each Gram negative pathogen in different nosocomial infections is shown in (Table 4). 
Table 4: Distribution of each Gram neagtive pathogen in different nosocomial infections

\begin{tabular}{|l|c|c|c|c|c|}
\hline \multicolumn{1}{|c|}{ Organism } & $\begin{array}{c}\text { RTI } \\
\text { No }(\%)\end{array}$ & $\begin{array}{c}\text { SSTI } \\
\text { No }(\%)\end{array}$ & $\begin{array}{c}\text { UTI } \\
\text { No }(\%)\end{array}$ & $\begin{array}{c}\text { BSI } \\
\text { No (\%) }\end{array}$ & $\begin{array}{c}\text { Total } \\
\text { No }\end{array}$ \\
\hline Escherichia coli & $08(17.4 \%)$ & $14(30.4 \%)$ & $24(52.2 \%)$ & $00(0 \%)$ & 46 \\
\hline Klebsiella species & $24(70.6 \%)$ & $04((11.8 \%)$ & $02(5.9 \%)$ & $04(11.8 \%)$ & 34 \\
\hline Acinetobacter species & $14(43.7 \%)$ & $06(18.7 \%)$ & $06(18.7 \%)$ & $06(18.7 \%)$ & 32 \\
\hline $\begin{array}{l}\text { Pseudomonas } \\
\text { aeruginosa }\end{array}$ & $12(54.5 \%)$ & $02(9.1 \%)$ & $06(27.3 \%)$ & $02(9.1 \%)$ & 22 \\
\hline Citrobacter species & $04(50 \%)$ & $04(50 \%)$ & $00(0 \%)$ & $00(0 \%)$ & 8 \\
\hline Total organisms & 62 & 30 & 38 & 12 & 142 \\
\hline
\end{tabular}

In CCU the most common isolate was Klebsiella species 14 (31.8\%) followed by Escherichia coli 12(27.3\%). In ICCU Escherichia coli was most frequently isolated 16 (42.1\%) followed by Klebsiella species 10 (26.3\%). The most common organism causing infection in NICU was Acinetobacter species $10(45.4 \%)$. Majority of the infections in SICU were caused by Escherichia coli 18 (32.1\%) followed by Acinetobacter species 10 (22.7\%). In PICU the organisms isolated was Acinetobacter species (1000\%). The distribution of isolates in different ICUs is shown in (Table5).

Table 5: Distribution of the isolates in different ICUs

\begin{tabular}{|l|c|c|c|c|c|}
\hline \multicolumn{1}{|c|}{ Organism } & $\begin{array}{c}\text { CCU } \\
\text { No (\%) }\end{array}$ & $\begin{array}{c}\text { ICCU } \\
\text { No (\%) }\end{array}$ & $\begin{array}{c}\text { NICU } \\
\text { No (\%) }\end{array}$ & $\begin{array}{c}\text { SICU } \\
\text { No (\%) }\end{array}$ & $\begin{array}{c}\text { PICU } \\
\text { No (\%) }\end{array}$ \\
\hline Escherichia coli (46) & $12(27.3 \%)$ & $16(42.1 \%)$ & $00(0 \%)$ & $18(32.1 \%)$ & $00(0 \%)$ \\
\hline Klebsiella species (34) & $14(31.8 \%)$ & $10(26.3 \%)$ & $08(36.3 \%)$ & $02(5.5 \%)$ & $0(0 \%)$ \\
\hline Acinetobacter species (32) & $06(13.6 \%)$ & $04(10.5 \%)$ & $10(45.4 \%)$ & $10(22.7 \%)$ & $02(100 \%)$ \\
\hline Pseudomonas aeruginosa (22) & $06(13.6 \%)$ & $08(21.0 \%)$ & $02(9.1 \%)$ & $06(16.6 \%)$ & $00(0 \%)$ \\
\hline Citrobacter species (08) & $06(13.6 \%)$ & $00(0 \%)$ & $02(9.1 \%)$ & $00(0 \%)$ & $0(0 \%)$ \\
\hline Total (142) & $44(100 \%)$ & $38(100 \%)$ & $22(100 \%)$ & $36(100 \%)$ & $2(100 \%)$ \\
\hline
\end{tabular}

\section{Antibiotic resistance pattern of Gram negative bacilli}

Among Gram negative bacilli maximum resistance was seen against cloxacillin , cephalosporins like cephalexin and cefuroxime 142 ( 100\%) followed by ampicillin 140( 98.6\%) and ciprofloxacin(94.4\%). Minimum resistance was seen against imipenem (26.8\%) followed by piperacillin - tazobactam (45.1\%) and amikacin (47.9\%). Among the Gram negative urinary tract infection isolates the resistance seen against nitrofurantoin was (21.05\%). Pseudomonas aeruginosa was more susceptible to piperacillin (63.6\%) as compared to other Gram negative isolates. (Fig. 4)

Among Escherichia coli isolates maximum resistance was seen against ampicillin, cloxacillin, cefuroxime and cephalexin $46(100 \%)$ followed by ceftriaxone $44(95.6 \%)$, piperacillin $(95.6 \%)$ and fluoroquinolones like ciprofloxacin and norfloxacin 44(95.6\%). Minimum resistance was seen against imipenem (0\%) followed by piperacillin -tazobactam and amikacin 18(39.1\%). Resistance seen against gentamicin and cotrimoxazole was 32 $(69.6 \%)$.

For Klebsiella species maximum resistance was seen against cloxacillin , cefuroxime and cephalexin 34(100\%) followed by ampicillin , ceftriaxone and ciprofloxacin 16(94.1\%).Minimum resistance was seen against imipenem 2(5.9\%) followed by piperacillin -tazobactam and amikacin and gentamicin 14(41.4\%).

For Acinetobacter species maximum resistance was seen against ampicillin, cloxacillin and cephalosporins $32(100 \%)$ followed by piperacillin $30(93.7 \%)$ and ciprofloxacin $28(87.5 \%)$. Minimum resistance was seen against imipenem $4(1.2 \%)$ followed by tetracycline $18(56.2 \%)$ and amikacin20 (62.5\%). The antibiotic reristance pattern is shown in Fig. 4. 
Fig 4: Antibiotic resistance pattern of Gram negative bacilli

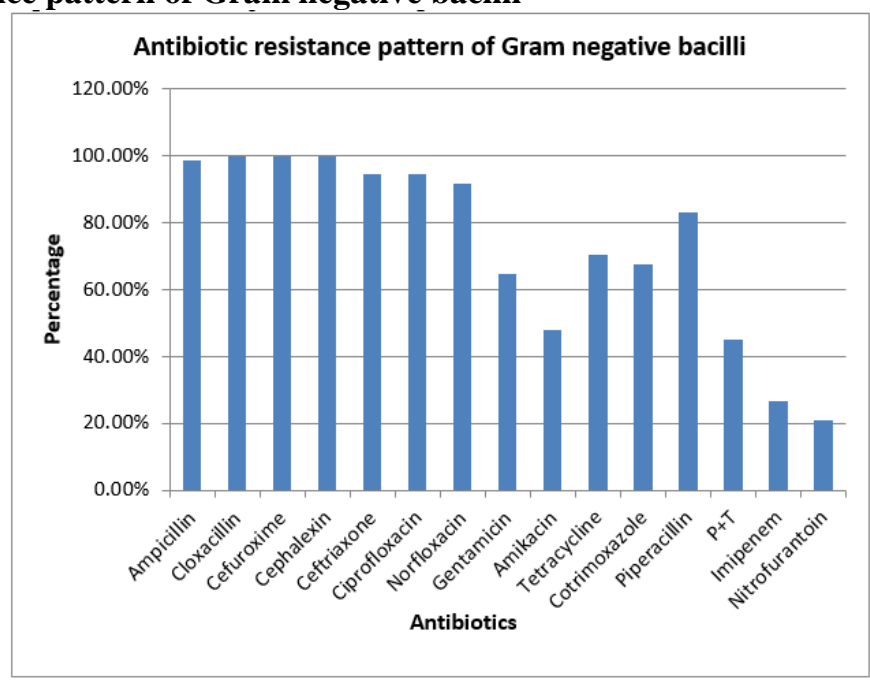

\section{Discussion}

Nosocomial bacterial infections are a major cause of morbidity in hospitalised patients. Patients in the intensive care units (ICUs) have a 5 to 7 fold higher risk of nosocomial infections compared with the average patients. $20-25 \%$ of the nosocomial infections develop in ICUs. By far the most important causative agents of nosocomial infections are bacteria. A large number of Gram negative bacteria like Klebsiella pneumoniae, Esch.coli, Citrobacter freundii, Pseudomonas aeruginosa and Acinetobacter baumannii are potential pathogens in hospitalised patients which can lead to respiratory tract infections, urinary tract infections, skin and soft tissue infections and blood stream infections. ${ }^{9}$

Antibiotic resistance in the intensive care units (ICUs) is a major worldwide problem. It has been found that the spread of drug resistant organisms in the ICUs is related to the widespread use of antibiotics. The rate of resistance in the ICUs is several fold higher than the general hospital setting. Effective eradication of therefore is of primary importance. ${ }^{10}$

In this study a total of 202 organisms were isolated from 192 various clinical samples. Most of the isolates were from respiratory samples $76(39.5 \%)$ [sputum 38 $(19.8 \%)$, endotracheal secretion $32(16.7 \%)$ and throat swab $6(3.12 \%)$ ] followed by pus samples $44(22.9 \%)$, urine $40(20.8 \%)$ and blood $32(16.7 \%)$.

Our data corelates with the results of study conducted by Zhanel GG et al. ${ }^{11}$ However in the results published by Sharma SK et al ${ }^{12}$ respiratory specimens were the most common followed by urine and blood. Another report by Patel BV et al ${ }^{5}$ highlights the variability in distribution of specimens where most of the isolates were from urine samples followed by blood and pus. The widespread use of tracheal intubation and mechanical ventilation to support the patients in ICUs increases the risk of nosocomial respiratory tract infections.
In the present study most of the samples obtained were from males $116(60.6 \%)$ and $76(39.6 \%)$ were from females. This is in consistence with the study conducted by Zhanel GG et al ${ }^{11}$, Pradhan N et al ${ }^{13}$ and Baghaei $\mathrm{R}$ et al ${ }^{14}$ where most of the isolates were from male patients. It is in contrast with the study conducted by Al-Jawady ZA et al $^{1}$ where most of the isolates were obtained from females.

The major age group was $\leq 1$ year which included 20 (20.9\%) samples followed by 41- 50 years and 61-70 years which included $13(13.5 \%)$ samples. It is in contrast with the study conducted by Zhanel GG et al ${ }^{11}$ where the major age group was 18-64 years. This is probably due to low level of immunity in $\leq 1$ year age group and higher incidence of serious illness in ageing population.

Nosocomial infections in Intensive care units are predominantly respiratory tract infections and in accordance with this, the most common nosocomial infection in the present study was respiratory tract infection 76(39.6\%) . It was followed by skin and soft tissue infection 44 (22.9\%), urinary tract infection 40 $(20.8 \%)$ and blood stream infection $32(16.7 \%)$. The widespread use of mechanical ventilation and endotracheal intubation in critically ill patients increases the risk of nosocomial respiratory tract infections. ${ }^{95}$ Comparable results have been published by Aksaray $\mathrm{S}$ et $a l^{15}$ and Gunseren $\mathrm{F}$ et $a l^{6}$. It is in contrast with the study conducted by Mythri $\mathrm{H}$ et $a l^{16}$ where the most common nosocomial infection was urinary tract infection followed by respiratory tract infection.

In the present study out of the 192 samples processed 202 organisms were isolated. From 182 samples single organism was isolated. 10 samples had mixed growth. The number of Gram positive isolates was $60(29.7 \%) .142(70.3 \%)$ Gram negative organisms were isolated .This predominance of Gram negative bacteria is coincident with the finding of some recent 
studies (Zhanel GG et al, ${ }^{11}$ Patel $\mathrm{BV}$ et $a l,{ }^{5}$ and $\mathrm{Al}$ Jawady ZA et $\left.a l^{1}\right)$.

Among the Gram negative isolates the members of Enterobacteriaceae like E. coli $46(22.8 \%)$ represented the most frequently isolated organism followed by Klebsiella species 34(16.8\%). Non fermenters like Acinetobacter species $32(15.8 \%)$ and P.aeruginosa 22 (10.9\%) were also isolated. The data is comparable to other studies. ${ }^{2,11}$ Members of Enterobacteriaceae are widely diffused in human body as normal flora, which make them one of the most important available endogenous bacteria ready for nosocomial infections in critically ill patients. ${ }^{2}$

While Pseudomonas are widely distributed in the environment, in water, medical instruments and machines like ventilator circuits, there are clear regional differences and variation in prevalence of P.aeruginosa. In the present study $P$. aeruginosa $(10.9 \%)$ were found. It is in contrast with study conducted by Patel BV et $a l^{5}$ and Mathur $\mathrm{P}$ et al. ${ }^{17}$ This may be due to variation in the local infection control measures which may alter the infection rates. ${ }^{2}$

Overall in the present study Esch.coli represented the most common isolate. It may be due to their wide prevalence in the hospital environment, and most of them represent a wide range of normal flora. In addition, their frequent resistance to antibiotic may play a role in their persistence and spread. ${ }^{2}$ It is in comparison with the studies conducted by Al- Jawady $\mathrm{ZA}$ et $a l^{1}$ and is in contrast with the studies conducted by Zhanel GG et $a l^{11}$ and Mathur $\mathrm{P}$ et $a l^{17}$ where S.aureus was the most common isolate.

In the present study highest occurrence of nosocomial infections was observed in CCU 52(27.1\%) followed by ICCU 48 (25\%). Majority of the respiratory tract infections were seen in ICCU 30 $(39.5 \%)$, skin and soft tissue infections in SICU 26(59.1\%), urinary tract infections in CCU 16 (40\%) and blood stream infections in NICU 30 (93.7\%).

In ICCU and CCU respiratory tract infection was the major infection 30 (39.5\%) and 28 (36.8\%) respectively, which is in accordance with the study conducted by conducted by Kucukates E et al ${ }^{18}$ where the percentage of respiratory tract infection in ICCU was $50.3 \%$. Mechanical ventilation, particularly prolonged coma or reduced conscious level, supine positioning, aspiration, pre-existing diseases like COPD, old age, malnutrition and use of nasogastric tubes are the predisposing factors for nosocomial respiratory tract infections. The organism may gain access into the lungs by one of the several routes like aspiration of oropharyngeal secretions, aspiration of gastric contents, inhalation, hematogenous spread and direct inoculation and exogenous penetration (eg: pleural space).

In SICU the major infection was skin and soft tissue infection $26(59.1 \%)$ which corelates with the study conducted by Iyer AP et al ${ }^{19}$ where the most common infection was surgical wound infection $(35.2 \%)$. During the dressing of wounds cross transmission occurs either by the hands of personnel or by contaminated instruments. Compromised membrane and skin barriers following the use of invasive devices can also lead to infections. ${ }^{20}$ On the other hand Bayram A et $a l^{20}$ concluded in their study that the most common infection in SICU was respiratory tract infection $(31.5 \%)$

In the present study in NICU, highest occurrence of blood stream infections was seen 30 (93.7\%). Risk factors include catheter insertion and care practices, products administered through the line, frequency of manipulation, age group, underlying disease, and severity of illness of the patient. In case of catheter induced infection, infection may occur as a result of migration of microorganisms from the insertion site along the percutaneous tract. This data is in consistent with the study conducted in Canada. ${ }^{21}$

In the present study Klebsiella species 24/62 (38.7\%) were the most common organism causing respiratory tract infections followed by Acinetobacter species 14/62 (22.6\%). The virulence factors in Klebsiella species responsible for respiratory tract infections are pilli and capsule. Type 1 pilli which are best investigated of the bacterial adhesions are responsible for binding of the bacteria to mucous or to epithelial cells of the respiratory tract. The findings are similar with the study conducted by Sharma SK et $a l^{12}$ and Patel BV et $a l^{5}$ where the major organism isolated from respiratory tract infections was klebsiella species $(58.1 \%)$ and $(34.0 \%)$ respectively. It is in contrast with the other studies conducted by Al- Jawady ZA et al $^{1}$ and Zhanel GG et al. ${ }^{2,11}$

Escherichia coli 14/30 (46.6\%) was the major organism isolated from skin and soft tissue infections followed by Acinetobacter species 6/30 (20.0\%). Esch.coli possess typical virulence determinants (adhesins such as P fimbriae, iron acquisition systems such as aerobactin, host defense avoidance mechanisms such as capsule, and toxins such as hemolysin) which can cause skin and soft tissue infections. This data in the present study correlates with the study conducted by Al-Jawady et $a l^{1}$ but is in contrast with the other studies. ${ }^{11,12}$

The most common organism isolated from urinary tract infection in the present study was Escherichia coli 24/38 (63.1\%) followed by Acinetobacter species 6/38 (15.7\%) and Pseudomonas aeruginosa 6/38 (15.7\%). With the help of type 1 pilli which act as virulence factor the bacteria is attached to urinary epithelial mucosa. This is in accordance with the studies conducted by Zhanel GG et al, ${ }^{11}$ Sharma SK et $a l^{12}$ and Al- Jawady ZA et al. ${ }^{1}$ The data shows variability with the study conducted by Patel BV et al. ${ }^{5}$

In the present study Acinetobacter species6/12(50\%) was the most frequently isolated organism from blood stream infections followed by 
Klebsiella species $4 / 12 \quad(33.3 \%) \quad$. Bacterial polysaccharide components are involved in attachment/persistence of bacterial on foreign materials (indwelling devices). They can colonise the polymer surface by formation of thick multilayered biofilm and track down the catheters causing bloodstream infection. This data is similar to the studies conducted by Zhanel GG et $a l^{11}$ but is in contrast with the other studies. ${ }^{2,12}$

In the present study maximum resistance was seen against cloxacillin, cephalosporins like cephalexin and cefuroxime $(100 \%)$ followed by ampicillin $(98.6 \%)$ and ciprofloxacin $(94.4 \%)$. The resistance arises due to prior exposure to both cephalosporins and fluoroquinolones. High resistance in Gram negative bacilli to commonly used antibiotics arises due to antibiotic selective pressure. The acquisition of resistance occurs easily through the transfer of mobile genetic elements, which permit cross-resistance to structurally unrelated antibiotics. It is similar to the studies conducted by Patel BV et $a l^{5}$ and Kucukates E et $a l .{ }^{18} \mathrm{It}$ is in contrast with the study conducted by Al- Jawady et $a l^{1}$ and Aksaray $\mathrm{S}$ et al $^{15}$ where ciprofloxacin had proved to be an effective drug with the resistance of $(28.5 \%)$ and (59.4\%). Minimum resistance was seen against imipenem $(26.8 \%)$ followed by piperacillintazobactam $(45.1 \%)$ and amikacin $(47.9 \%)$. The high level of sensitivity may be due to less frequent use of such antibiotics in hospital. This is in accordance with the previous studies conducted by Dutta $\mathrm{P}$ et $a l^{2}{ }^{2} \mathrm{Al}-$ Jawady ZA et al, ${ }^{1}$ Patel BV et al, ${ }^{5}$ Kukucates E et al, ${ }^{18}$ Gunseren $\mathrm{F}$ et $a l^{11}$ and Aksaray $\mathrm{S}$ et $a l^{15}$ where imipenem was the most effective drug.

Nitrofurantoin is an effective drug against urinary tract infection.Most of the Esch.coli in urine samples were found to be susceptible to nitrofurantoin compared with other Gram negative isolates in urine (91.7\%). For Klebsiella species resistance seen against gentamicin is comparatively low as seen in other Gram negative bacilli $(41.4 \%)$. This is similar to the study conducted by Kukukates E et al $^{18}(20 \%)$ and is in contrast with the study conducted by Datta $\mathrm{P}$ et $a l^{2}$ where among all Gram negative isolates maximum resistance against gentamicin (91.7\%) was seen in Klebsiella species.

Pseudomonas aeruginosa was more susceptible to piperacillin $(63.7 \%)$ as compared to other Gram negative isolates. It is similar to the study conducted by Al- Jawady ZA et $a l^{l}$ where maximum susceptibility was seen $(40 \%)$ but is in contrast with the study conducted by Sheth KV et $a l^{13}$ where the resistance seen was $(100 \%)$ and Datta $\mathrm{P}$ et $a l^{2}(64.3 \%)$.For Acinetobacter species resistance against tetracycline (56.2\%) was lower compared to other isolates which is comparable to the result given by Kukukates E et al ${ }^{18}$ where the resistance seen was $(68.4 \%)$ but is in contrast with the study conducted by Patel BV et $a l^{5}$ where high resistance to tetracycline was seen in Acinetobacter species (80\%) compared to other Gram negative isolates.

\section{Conclusion}

To put into a nutshell nosocomial infections in ICUs are foremost aspect which needs to be tackeled carefully and efficiently by the healthcare professional for the betterment of patients who are hospitalized. The prescribing of antibiotics in ICUs is usually empiric. Therefore the ongoing surveillance of antibiogram of bacteria is fundamental effort to monitor changes in susceptibility patterns and guide the clinician in choosing empirical therapy appropriately. Appropriate antibiotic utilization in ICUs is crucial in ensuring optimal outcome and preventing emergence of multidrug resistance bacteria

Funding: No funding sources.

Conflict of interest: None declared.

\section{References}

1. 1. Al-Jawady ZA, Al- Habib HM .Antibiogram Profiles of Bacterial Isolates from Intensive Care Units in Mosul Teaching Hospitals. Raf J Sci 2012;23:52-9.

2. Datta P, Rani H, Chauhan R, Gombar S, Chander J. Health- care- associated infections: Risk factors and epidemiology from an intensive care unit in Northern India. Indian J of Anaes 2014;58:30-5.

3. Kaul S, Brahmadathan KN, Jagannati M, Sudarsanam TD, PitchamuthuK, Abraham OC et al . One year trends in the gram-negative bacterial antibiotic susceptibility patterns in a medical intensive care unit in South India. Indian J Med Microbiol 2007;25:230-35.

4. Dwivedi M, Mishra A, Singh RK, AzimA, Baronia AK, Prasad KN. Nosocomial cross-transmission of Pseudomonas aeruginosa between patients in a tertiary intensive care unit. Indian J Pathol Microbiol 2009;52:509-13.

5. Patel BV, Patel PG, Raval PN, Patel MH, Patel PH, Vegad MM. Bacteriological profile and antibiogram of Gram negative organisms isolated from neurology intensive care unit with special refrence to multidrug resistant organisms. Natl J Med Res 2012;2:335-38.

6. Gunseren F, Mamikoglu L, OzturkS, Yucesoy M,Biberoglu K, Yulug N et al .A survillence study of antimicrobial resistance of Gram- negative bacteria isolated from intensive care units in eight hospitals in Turkey. J Antimicrobial Chemotherapy 1999;43:373-78.

7. Collee JG, Doguid JP, Fraser AG and Marmion BP. Mackie and Mc Cartney. Practical medical microbiology: $14^{\text {th }}$ ed. Churchill Livingstone, USA: Elsevier; 1989.

8. CLSI. Performance Standards for Antimicrobial Disc Susceptibility Tests; Approved standard $11^{\text {th }}$ edition.CLSI document M02-A11.Wayne, PA: Clinical and Laboratory Standards Institute; 2012.

9. Sharma DK, Tiwari YK, Vyas N, Maheshwari RK. An investigation of the incidence of Nosocomial infections among the patients admitted in the intensive care unit of a tertiary care hospital in Rajasthan, India. Int J Curr Microbiol App Sci 2013;2:428-35.

10. Shrestha B, Pokhrel B, Mohapatra T.Study of nosocomial isolates of Staphylococcus aureus with special reference to methicillin resistant S.aureus in a tertiary care hospital in Nepal. Nepal Med Coll J 2009;11:123-26.

11. Zhanel GG, DeCorby M, Laing N, Weshnoweski B, Vashist R, Tailor F et al .Antimicrobial resistant pathogens in Intensive Care Units in Canada: Results of 
the Canadian National Intensive Care Unit (CAN-ICU) study, 2005-2006.Antimicrob. Agents Chemother 2008;52:1430-37.

12. Sharna SK, Hadda V, Mathur P, Gulati V, Sahney C. Profile of microorganisms in intensive care unit of a level -1 trauma centre: A retrospective study. Indian J Crit Care Med 2013;17:87-91.

13. Pradhan NP, Bhat SM, Ghadage DP. Nosocomial infections in medical ICU: A retrospective study highlighting their prevalence, microbiological profile and impact on ICU stay and mortality. J Assoc Physicians India 2014;62:18-21.

14. Baghaei R, Mikaili P, Nourani D, Khalkhali HM. An epidemiological study of nosocomial infections in the patients admitted in the intensive care unit of Urmia Imam Reza Hospital: An etiological investigation. Ann Biol Res 2011;2:172-8.

15. Aksaray S, Dokuzoguz B, Guvener E, Yucesoy M, Yulug $\mathrm{N}$, Kocagoz $\mathrm{S}$ et al .Survillence of antimicrobial resistance among Gram negative isolates from intensive care units in eight hospitals in Turkey. J Antimicrobial Chemotherapy 2000;45:695-99.

16. Mythri H, Kashinath KR. Nosocomial infections in patients admitted in intensive care unit of a tertiary health center, India. Ann Med Health Sci Res 2014;4:738-41.

17. Mathur P, Kapil A, Das B.Nosocomial bacteraemia in intensive care unit patients of a tertiary care centre. Indian J Med Res 2005;122:305-8.
18. Kukukates E, KocazeybekB. High resistance rate against 15 different antibiotics in aerobic Gram-negative bacteria isolates of Cardiology Intensive Care Unit patients. Indian J Med Microbiol 2002;20:208-10.

19. Iyer AP, Baghallab I, Albaik M, Kumosani T. Nosocomial Infections in Saudi Arabia Caused by Methicillin Resistance Staphylococcus aureus (MRSA). Clin Microbiol 2014;3:146. doi:10.4172/23275073.1000146.

20. Bayram A, Balei I. Patterns of antimicrobial resistance in a surgical intensive care unit of a university hospital in Turkey. BMC Infectious Dis 2006;6:155.

21. Cassidy K.Survillence of central venous catheter associated blood stream infection (CVC-BSI) in intensive care units. CNISP CVC-BSI Survillence protocol 2011:120.

22. Sheth KV, Patel TK, Malek SS, Tripathi CB. Antibiotic Sensitivity Pattern of Bacterial Isolates from the Intensive Care Unit of a Tertiary Care Hospital in India. Tropical $J$ Pharmaceut Res 2012;11:991-99.

How to cite this article: Afroz Z., Metri B., Gilani F., P. Jyothi. Bacteriological profile of gram negative nosocomial isolates from intensive care units and their antibiogram in a tertiary care hospital of South India. Int J Med Microbiol Trop Dis 2018;4(4):243-50. 